\title{
A guerra das mães: dor e política em situações de violência institucional"
}

\author{
Adriana Vianna** \\ Juliana Farias**
}

\section{Resumo}

O artigo busca discutir relações entre "violência" e "gênero" a partir de situações envolvendo formas de "luta por justiça" $e$ expressão da dor por familiares de pessoas mortas pela polícia militar no Rio de Janeiro. Acompanhando situações diversas em que tais familiares, agrupados em redes de apoio e de organização política, buscam a condenação judicial dos policiais que mataram seus filhos, irmãos ou sobrinhos, procuramos refletir sobre o trabalho social de construção da "violência" e ilegitimidade desses assassinatos como inextricavelmente ligados às gramáticas de gênero e, em especial, ao protagonismo simbólico das "mães".

Palavras-chave: Violência, Gênero, Justiça, Família.

\footnotetext{
* Recebido para publicação em 24 de julho de 2011, aceito em 12 de setembro de 2011. As autoras agradecem a leitura e os comentários valiosos de Sílvia Aguião, Letícia Ferreira, Paula Lacerda, Angela Facundo e, muito especialmente, de Maria Gabriela Lugones.

** professora do PPGAS/MN/UFRJ. adrianavianna@gmail.com

**** doutoranda do PPGSA/IFCS/UFRJ. farias.ju@gmail.com
}

cadernos pagu (37), julho-dezembro de 2011:79-116. 
A guerra das mães

The Mothers' War: Pain and Politics in Situations of Institutional Violence

\begin{abstract}
This work discusses relations between "violence" and "gender" by focusing situations involving forms of "struggle for justice" and the expression of pain by relatives of persons killed by Rio de Janeiro's military police. By following different situations where those relatives, connected in networks of support and political organization, seek the conviction of the policemen that have killed their sons, brothers or nephews, we reflect on the work of social construction of "violence" and illegitimacy of these murders as being inseparably connected to grammars of gender, especially to the symbolic protagonism of "mothers".
\end{abstract}

Key Words: Violence, Gender, Justice, Family. 


\section{1. "Me tiraram o direito de ser Mãe"}

Rio de Janeiro, sábado de sol. Chegamos, atendendo à convocação de uma rede de militantes, à manifestação em frente a uma unidade sócio-educativa para jovens infratores para protestar contra a morte, sob tortura, de Pedro, ocorrida há cerca de três anos, em 2008, naquela mesma unidade. ${ }^{1}$ Como dado recente, havia a denúncia feita pelo Ministério Público de seis agentes disciplinares e o ato pretendia não apenas marcar esse fato, mas exigir a exoneração desses mesmos agentes. Um carro de som havia sido providenciado e, microfone em punho, Celeste, a mãe do rapaz morto, fazia uma de suas várias falas ao longo do dia. Ora dirigindo-se aos próprios agentes que estariam na porta $e$ dentro dos imensos muros de concreto e arame farpado, ora aos familiares que estariam visitando outros jovens, relembrava as lesões sofridas pelo filho, as justificativas levantadas pelo defensor dos agentes, de que teria ocorrido apenas uma contenção e um castigo proporcionais ao porte do rapaz, e conclamava a todos os que soubessem de outras violências, fossem eles familiares ou funcionários, a denunciarem o fato.

Em suas falas, assim como em uma das três faixas dispostas ao longo do muro defronte à instituição, o termo "mãe" ganhava destaque. A frase "Me tiraram o direito de ser Mãe" fazia parte de

\footnotetext{
1 A rede a que nos referimos é a Rede de Comunidades e Movimentos contra Violência - movimento social que atua no Rio de Janeiro desde 2004, formado majoritariamente por familiares de vítimas de violência policial em favelas. No ato em questão estava envolvido também o movimento MOLEQUE - "Movimento de Mães pelos Direitos dos Adolescentes no Sistema Sócio-educativo", que atua no Rio de Janeiro desde 2003. No artigo optamos por trocar os nomes de militantes, familiares e jovens mortos, considerando que muitos casos ainda estão em andamento em instâncias policiais e judiciais. As pessoas que ocupam cargos públicos - deputados, promotores, juízes etc. - não estão citadas nominalmente, mas são facilmente identificáveis. Como os atos que os envolvem, porém, são de natureza pública, não nos preocupamos em adotar maiores estratégias de ocultamento.
} 
uma dessas faixas, que trazia também os dizeres "A maior forma de covardia é agindo na fraqueza do outro/De que adianta a lei se ela não é respeitada?". " Com sua voz forte e decidida, Celeste falava de sua dor e de sua indignação como mãe de Pedro, mas também como mãe de outros filhos, um dos quais teria dito, ainda criança, desejar cometer crimes apenas para ser levado para a mesma instituição e vingar o irmão, o que a teria levado ao desespero. Falava, ainda, em nome de um coletivo ao mesmo tempo vago, porém identificável de modo mais ou menos concreto em outros rostos que a acompanhavam, prestando solidariedade, ao dizer: "nós, mães, estamos cansadas de ver nossos filhos sofrendo, de ver as arbitrariedades cometidas por vocês, pagos com os nossos impostos". Construía, por antagonismo, certa associação com mães ausentes, as dos próprios agentes responsáveis pela morte de seu filho, ao dizer em mais de uma ocasião nesse dia ter pena delas, por terem "botado esses monstros no mundo". ${ }^{3}$ Por fim, mencionava a presença no ato de sua própria mãe, que teria criado nove filhos, sem que nenhum "virasse bandido".

2 As outras duas faixas exibiam: "Vossa Excelência Sérgio Cabral e o Secretário de Segurança: Agentes do Estado mata e nada é feito/Quem é o meliante da história?" e "Familiares e amigos de Pedro vem pedir ao MP a exoneração dos agentes do Degase que o assassinaram no dia 1\%/jan/08".

3 Nesse circuito político protagonizado por familiares de vítimas de violência institucional, as referências às mães dos agentes do Estado (das mães de policiais à mãe do governador) são trazidas a público de inúmeras formas - algumas vezes explicitando as assimetrias demarcadas de antemão, outras vezes tentando sublimá-las através da conexão pela maternidade e/ou pela dor (nos casos de mães de agentes mortos em serviço, por exemplo). O teor de complexidade desse campo - que também é redesenhado pela polaridade "asfalto" X "favela" se revela de forma esclarecedora na análise desenvolvida por Leite (2004), a respeito de diferentes coletivos formados por mães de vítimas na cidade do Rio de Janeiro. Para além das incompatibilidades políticas inerentes aos coletivos observados, Leite explora as imbricações entre "solidariedade" e "religião" e seu rebatimento na tradução de "justiça" como um substituto para "vingança". 
Longe de ser um fato isolado, o acionamento da condição de mãe como elemento de autoridade moral em atos políticos nos fala de trânsitos relevantes em cenários contemporâneos: entre dor pessoal e causas coletivas; entre sofrimentos e direitos; entre formas e dimensões distintas do luto, aqui tomado como processo inextricavelmente individual $e$ social. ${ }^{4}$ Celeste, como muitas outras mães e familiares de vítimas de violências cometidas por atores $e$ instituições de Estado, performava ali, em frente ao local do assassinato do filho, o que significava essa singular condição materna: falava da necessidade de "lutar" como imperativo dessa mesma condição, trazia a imagem do filho colada ao corpo, estampada na camiseta feita para a ocasiáo, descrevia o desespero inscrito no passado - o dia da morte do filho, sempre relembrado - e no presente, na preocupação com o outro filho, mas também no conclamar a que outros tenham coragem de fazer denúncias, para impedir que o que ocorreu com seu filho se repita com outras pessoas.

Do que ela nos falava e, sobretudo, como ela nos falava com seu corpo, sua roupa, sua escolha das palavras - ecoa, desse modo, em outros atos, depoimentos, cenas e situações vistas por nós e por outros pesquisadores diversas vezes. ${ }^{5}$ Suas ações fazem

4 Como chama atenção Butler (2004:21-23), a perda instaura uma dúvida primordial sobre quem é esse "eu" que passa a existir sem "você". O luto, desse modo, não apenas se inscreve na solidão pessoal, mas também atua sobre um senso complexo de comunidade.

${ }^{5} \mathrm{O}$ protagonismo dos familiares de vítimas de violência institucional - em especial das mães - vem despertando a atenção de diversos pesquisadores $e$ ativistas políticos, estimulando assim tratamentos cuidadosos desse tema em trabalhos impressos e audiovisuais de fundamental importancia para $\mathrm{o}$ aprofundamento do debate e para a amplificação das questões a ele inerentes. Dentre essas produções, destacamos: a coletânea "Um mural para a dor: movimentos cívico-religiosos por justiça e paz" (organizada, em 2004, por Patricia Birman e Márcia Pereira Leite); o livro "Auto de resistência: relatos de familiares de vítimas da violência armada" (organizado, em 2009, por Barbara Musumeci Soares, Tatiana Moura e Carla Afonso); o livro "Mães de Maio: do luto à luta" (organizado, em 2011, pelo Movimento Mães de Maio - SP); o documentário "Entre Muros e Favelas" (dirigido por Susanne Dzeik, Kirsten 
parte de um repertório de experiências e recursos políticos que circulam através de redes ativistas, que se replicam em dinâmicas de aprendizado e solidariedade entre pessoas que, a partir de dado momento e movidas por condições específicas, passam a se ver como parte mais ou menos exata de um "coletivo". "Nós, mães", "Nós, familiares" ou, mais raramente, "Nós, familiares e amigos" compõem sujeitos simultaneamente da dor pessoal e da ação política. Trazem para a cena pública, como capital primordial, a história de suas relações, narrada sempre a partir de um evento extraordinário que interrompeu o que se imaginava ser o curso natural dessas relações (Das, 2007), que levou embora investimentos morais e afetivos profundos e que reformulou o próprio sentido de tempo que se tinha antes, agora marcado não só por uma data inesquecível, mas pela penosa sensação de esperar por uma reparação pública que quase nunca chega.

Estar presente em situações em que esses coletivos são postos em cena é acompanhar e atuar através de gramáticas e linguagens corporais dos afetos, tanto em termos das emoções que são tematizadas e dramatizadas - a indignação, a dor da perda, a saudade, a revolta com o que parece ser o descaso alheio quanto das relações prévias que dão sentido à participação na "luta" ou das relações que se estabelecem a partir dela. Abraços e agradecimentos pela presença nos atos, audiências e julgamentos; falas sobre os desgastes, mas também sobre a importância de comparecer às situações envolvendo outras mães e familiares; o uso compartilhado de símbolos como as camisetas com fotos da

Wagenschein e Márcio Jerônimo); e o documentário "Luto como mãe" (dirigido por Luis Carlos Nascimento). Destacamos ainda trabalhos produzidos a partir do contexto argentino, como os de Catela (2001) e Bermúdez (no prelo), bem como trabalhos acadêmicos mais recentes: Ferreira (2011), Lacerda (2011), Araujo (2008), Farias (2008) e Freire (2010).

6 Usamos "luta" aqui como categoria nativa corrente no campo, atentando também, como nos indica Comerford (1999), que essa é uma categoria polissêmica que pode ser acionada para se falar da luta pessoal, da vida como uma luta e da luta política. 
vítima em julgamentos e atos centrados em um caso específico, ou cartazes e faixas que podem ser levados por não familiares em atos coletivos etc. falam-nos dessa dupla tessitura, em que os compromissos que já existiam levam à rua e os compromissos feitos na rua abrem as portas das casas, os álbuns de fotos e algo sobre outras histórias familiares e pessoais que não cabem na "luta".

$\mathrm{O}$ que procuraremos apresentar aqui parte do reconhecimento de nosso próprio enredamento nesse processo. Trafegando por cenas variadas, vamos sendo chamadas a nos colocar como parte desses corpos coletivos, sem que nunca, porém, cisões decisivas deixem de estar à vista. "Você está aqui porque perdeu alguém?" foi perguntado a nós duas em diferentes ocasiões. A resposta negativa marca uma distinção que não pode jamais ser ultrapassada: a solidariedade é valorizada, mas não estabelece o mesmo tipo de vínculo, algo que só o compartilhamento daquilo que é tomado como uma dor ímpar pode fazer. Em outras situações, porém, o que pareceria ser o mais evidente pode ser simbolicamente apagado: somos todos $e$ todas tornados "mães" na fala de um operador do direito em meio a um julgamento, inclusive os homens presentes. ${ }^{7}$

$\mathrm{O}$ "direito de ser Mãe" que foi tirado de Celeste condensa dramaticamente esses jogos entre o pessoal e o coletivo; entre o sentimento e a lei; entre o corpo-relação reconhecido (o direito) e o corpo-relação (Mãe, com maiúscula) que não cabe nas palavras, que se expressa como unidade moral e afetiva que só pode ser entendido por seus iguais ou por ninguém, como às vezes nos é colocado de diversos modos. Tentar entender algo desses jogos de composição e contraposição implica, necessariamente, pensá-los como inscritos em dinâmicas de gênero que modelam os corpos, as cartografias poéticas e pragmáticas presentes nas cenas coletivas e públicas, o tecido das obrigações morais para com

7 Essa situação será detalhada no item 3 do artigo. 
mortos e vivos e, por fim, o próprio sentido dessas "lutas" estabelecidas a partir e contra a perda.

$\mathrm{Na}$ parte que se segue, procuramos pensar sobre algumas estratégias empregadas para criar espaços de reconhecimento do valor político dessas perdas, vendo-as como parte de uma economia simbólica mais complexa que se assenta na projeção dos domínios "doméstico" e "público" como ordenadores de zonas de legitimidade para as dores encenadas $e$ vividas nesses dramas.

\section{2. "Enquanto o Estado está lá sentado..."}

Acompanhar e participar de atos e situações estratégicas envolvendo essa rede de militantes e familiares de vítimas de violência policial embrenhou-nos em contextos que trazem certas marcas recorrentes. Antes de tudo, lidamos primordialmente mesmo que não exclusivamente - com cenas públicas ${ }^{8}$, marcadas por um processo dinâmico de fabricação de unidades $e$ antagonismos relacionalmente definidos. Audiências judiciais, julgamentos, batalhões da Polícia Militar, atos de protesto em frente a unidades da polícia, como a Chefia da Polícia Civil, do Degase, eventos das comissões de Direitos Humanos da ALERJ e da Câmara dos Deputados, diferentes secretarias municipais e estaduais e ONGs de Direitos Humanos, entre outros, fazem parte do percurso em que tal militância é exercida e, por isso, traçaram também nossa agenda mais visível de pesquisa. ${ }^{9}$

8 Procuramos considerar, nos limites desse artigo, que tais cenas estão marcadas por certas exigências específicas que estabelecem condições para uma boa "apresentação de si". Nesses termos, procuramos estar atentas a mudanças de atitude que envolvem o falar em público, não explorando nesse espaço outras performances relevantes, como as estabelecidas pelos comentários paralelos que ocorrem durante uma apresentação pública ou que têm lugar na preparação para um "evento" ou quando ele se desfaz. Para uma discussão conceitual e metodológica sobre o tema, ver Goffman (1974).

9 O artigo está ligado a projetos distintos de pesquisa: no caso de Vianna, o projeto "Às portas dos direitos: as dinâmicas entre relações de gênero, redes 
Do ponto de vista de mães e demais familiares, esse trânsito implica processos claros de domínio crescente de códigos de conduta e de elaboração de estratégias para fazer-se ouvir. Se, com o caso de Celeste, mencionamos rapidamente algumas dessas estratégias usadas em uma cena com demarcações específicas, em outros momentos aprendemos sobre a relevância de acionar recursos distintos, como a demonstração do controle sobre os trânsitos burocráticos necessários para que um processo "ande" ou para que uma morte específica possa ser reconhecida como parte de um problema social e político mais amplo. Tais processos de aprendizado e uso de recursos dramáticos dependem em muito de características pessoais, mas, como vamos entendendo na medida em que somos também educadas e socializadas nessas diferentes instâncias e ocasióes, eles obedecem a scripts relativamente regulares, passados de modo mais ou menos explícito de participantes mais antigos para mais recentes.

Detalhes do que pode ser transmitido fazem a costura desses processos de aprendizado, como a passagem, ao final de uma reunião, de um caderno anotado à mão com números de telefones e e-mails de jornalistas, delegados, defensores públicos, promotores públicos, advogados de ONGs, chefes de gabinetes, secretários, enfim, diferentes contatos relevantes desse campo. Da agenda até é possível deduzir a quem é habitual recorrer, mas em que momentos e de que forma recorrer é algo que se aprende a fazer (e rapidamente se acostuma a fazer) nesse cotidiano de peregrinações institucionais. E, ainda que pese a recomendação

sociais, instituições de Justiça e ação política”, financiado pela FAPERJ através do edital Jovem Cientista do Nosso Estado, 2010 e a bolsa de produtividade do CNPq, nível 2, "Instituições de justiça, redes sociais e relações de gênero: uma antropologia da experiência dos 'direitos' e do fazer político"; no caso de Farias, o projeto de tese "Direitos Humanos, Estado e Favelas: interlocuções a partir da atuação de familiares de vítimas de violência policial", realizado a partir de 2009 no PPGSA/IFCS/UFRJ, com bolsa do CNPq e sob orientação do Prof. Luiz Antonio Machado da Silva. 
para ninguém se esquecer de "protocolar"10 um documento, outras preocupações mais sutis e que podem equivocadamente não serem consideradas parte do aprendizado da política vão preenchendo as bordas desse percurso, inscrevendo no feminino esse fazer militante. É o caso, entre outros, da estratégia adotada por parte das mulheres que compõem esse coletivo de levar dentro da bolsa um sapato de salto. Mais chique do que aqueles rasteiros e mais confortáveis para serem usados nas caminhadas diárias entre uma reunião e outra, idas emergenciais a alguma favela, sem contar o próprio trajeto - de ônibus ou trem, geralmente - de suas casas para o centro do Rio, o sapato de salto é retirado da bolsa, por exemplo, na porta de entrada no Ministério Público. Ao final do compromisso, a destroca de sapatos se repete no mesmo lugar.

Se a mudança de sapatos parece materializar (e mesmo fetichizar) o trânsito entre os espaços físicos e políticos a serem ocupados, outras formas de "entrar em cena" podem envolver o fazer-se notar e ouvir em situações nas quais inicialmente lhes teria sido reservado o espaço passivo de audiência, como figurantes ou ouvintes. Nesses casos, o acionamento da condição de mãe como ator político é o fator primordial para a ação, mesmo que não seja suficiente a priori, exigindo o uso de certos recursos estratégicos e habilidades aprendidas. Esse foi o caso da participação de Teresa (cujo filho foi morto por policiais há quase dez anos em uma favela da zona norte carioca) em uma audiência pública organizada pela Comissão de Defesa dos Direitos Humanos e Cidadania da Assembléia Legislativa do Rio de Janeiro, em 2009. Em um dado momento da audiência, Teresa levantou-se, caminhou na direção da presidência da audiência e entregou um bilhete para o deputado que ocupava o lugar de vice-presidente

\footnotetext{
${ }^{10}$ Nesse circuito específico, a ação de "protocolar" um documento significa entregá-lo na instituição devida, se certificar de que o mesmo chegou ao destinatário previsto e solicitar a assinatura daquele que o recebeu na cópia do documento que será arquivada pela militância.
} 
na mesa. Após a leitura do mesmo, o parlamentar balançou a cabeça fazendo sinal de afirmação. Minutos depois, o presidente da audiência tornou público o combinado que havia sido realizado em silêncio a partir do bilhete:

vou conceder a palavra para que você possa - você tem toda a legitimidade como mãe de uma vítima - possa falar. Não estava previsto, mas é evidente, a gente abre para que você possa falar daqui a pouco.

Assim como o presidente da audiência e a grande maioria dos presentes, Teresa sabia que "como mãe" - especialmente "como mãe de uma vítima" - ela realmente tinha legitimidade para falar naquela audiência. Mais interessante foi a maneira elegante com a qual Teresa desconstruiu um problema que estava colocado: o fato de nenhum familiar de vítima de violência policial fazer parte da composição original das falas oficiais naquela audiência. Caso fosse seguir estritamente os tais "códigos de conduta pré-estabelecidos", Teresa não teria falado em público naquele dia, motivo pelo qual merece atenção especial essa tomada de voz através de um bilhete escrito à mão.

Mas não só essa estratégia para "driblar" o protocolo oficial merece destaque nessa situação. É significativa também a construção da apresentação pública que preenche o primeiro trecho da fala de Teresa, explicitando a legitimidade que ela possui perante os diferentes coletivos cariocas formados por mães e demais familiares de vítimas de violência policial - tanto pelos anos de militância que marcam sua trajetória, quanto pela competência em proferir discursos marcantes durante eventos públicos. Tal legitimidade permite, por exemplo, que Teresa se sinta à vontade para se colocar tanto na primeira pessoa do singular, quanto na primeira pessoa do plural. De fato, Teresa naquela audiência falava em nome dos diferentes coletivos de mães de vítimas existentes na cidade do Rio de Janeiro e um ponto decisivo para essa interpretação é o fato de ela não se 
propor a denunciar publicamente a ação desse ou daquele policial envolvido na morte do seu filho. ${ }^{11}$

Outro movimento que identificamos na fala de Teresa configura-se a partir de sua habilidade para transitar entre o caso particular do seu filho e os demais casos semelhantes de violência policial - as "centenas de milhares de casos", como ela coloca realizando a "des-singularização do caso", apontada por Boltanski (2000 [1990]) como condição fundamental para o "engrandecimento" da denúncia, para sua repercussão pública. É interessante observar, portanto, que o acionamento da legitimidade dos "laços primordiais" (Geertz, 1978) tanto direciona o discurso para o caso particular (quando o discurso é preenchido por "meu filho"), como também se torna um recurso utilizado nos momentos que correspondem à "des-singularização" do caso, afinal, é a condição de "mãe" que conecta aquela mãe que faz o discurso às outras mães e demais familiares de vítimas que ali estão sendo representados.

O discurso de Teresa é composto por uma infinidade de elementos que, seguindo essa linha interpretativa desenvolvida por Boltanski (id.), são determinantes para a repercussão pública de uma denúncia: a maneira como Teresa se dirigiu aos presentes; o que valorizou para construir a apresentação de si; que recursos discursivos acionou para localizar sua fala; se falava em causa própria ou em nome de um coletivo; como e quando se deslocava do caso particular para o geral.

Cada uma dessas estratégias atua a favor do engrandecimento da denúncia e/ou de sua denunciante, mas nem sempre esse processo se realiza de forma bem-sucedida. É

\footnotetext{
${ }^{11}$ Como chama atenção Bourdieu (1984:49-55), o trabalho de constituir um representante - e de constituir-se enquanto representante - implica um trabalho de delegação e de apagamento relativo das fronteiras entre o grupo representado e o representante. Para poder se identificar ao grupo e dizer "eu sou o grupo" ou "eu sou, então o grupo é", o mandatário deve se anular no grupo, declarar "não existe senão o grupo". Nesse sentido, a modéstia é, mais que um atributo pessoal, uma obrigação do "cargo".
} 
importante ressaltar que apesar de não estarmos baseando diretamente (nem integralmente) esta análise no "sistema actancial da denúncia" operado por Boltanski (2000 [1990]) ${ }^{12}$, levamos em conta a necessidade do "ajustamento" entre as dimensões dos diferentes "actantes" para que a denúncia seja escutada. Algumas considerações do autor a respeito desse "ajustamento" chamam atenção tanto para o risco do exagero nas estratégias de engrandecimento do denunciante, quanto para palavras ou linguagens que revelam ausência de autocontrole do denunciante.

Nesse sentido, os anos de militância de Teresa realmente contribuíram para que sua intervenção na audiência fosse bemsucedida. Ainda que os sentimentos enriqueçam as gramáticas políticas dos familiares, naquele momento era importante conseguir conter a emoção: muito choro, ou um tom de voz muito elevado, além de atrapalhar a própria execução da fala, poderiam desqualificar os argumentos fortes da denúncia. Sendo assim, é fundamental destacar o domínio de Teresa sobre informações técnicas, dados quantitativos, procedimentos formais de encaminhamento de um inquérito policial e de um processo jurídico etc. - pois a articulação entre esse domínio e a capacidade de "dosar" a explicitação da emoção torna evidente sua competência para ocupar o lugar de representante dos familiares de vítimas naquela audiência pública.

Não é nosso objetivo aqui, porém, dissecar exaustivamente esses diferentes recursos e processos de transmissão de conhecimento, mas sim indicar a importância de pensá-los como parte de um jogo complexo de elaboração de atuações públicas que tornam possível a produção $e$ a inscrição das "mães $e$ familiares de vítimas" como atores políticos em arenas variadas.

12 Recorrendo ao termo "actante" no sentido atribuído por Latour (1984), Boltanski (2000 [1990]:247) explica que "uma denúncia instaura um sistema de relações entre quatro "actantes": 1) o que denuncia; 2) aquele em cujo favor se realiza a denúncia; 3) aquele contra quem se apresenta; 4) aquele a quem se dirige", designando-os respectivamente como "denunciante", "vítima", "perseguidor" e "juiz". 
Usando recursos estéticos muito distintos, as falas de Celeste em frente à instituição onde seu filho foi morto e de Teresa na audiência pública inscrevem-se em um mesmo processo dinâmico de construção de si mesmas enquanto pessoas que merecem ser vistas e ouvidas por atores dispostos em posições variadas de poder. Nesses termos, suas atuações apontam não apenas para a heterogeneidade de recursos políticos e simbólicos a serem acionados em contextos singulares, mas para a busca, em medidas desiguais em cada caso, do ajuste entre as narrativas sobre suas dores pessoais e sobre as "causas" que exigem reconhecimento $e$ resposta.

Ao longo desse processo, em que pese a diversidade de atores, lócus e arenas envolvidos, duas unidades simbólicas vão sendo reificadas como entidades discursivas centrais: "as mães" $e$ "o Estado". Gostaríamos, assim, de nos deter agora nessa relação, considerando não a polissemia e a dimensão historicamente constituída do "Estado", mas sua fabricação discursiva como pólo antagônico às "mães". Tal antagonismo alimenta-se de duas representações interconectadas que se expressam, em diferentes momentos, sob a forma de acusações: a primeira delas de ser o Estado o responsável direto pela morte em si dos seus filhos e familiares; a outra, de reforçar a ilegalidade e a injustiça que envolveriam essas mesmas mortes, ao não condenar os culpados e ao não se esforçar para apurar as condições em que a violência fatal foi exercida.

"Enquanto o Estado está lá, sentado, comendo e bebendo do bom e do melhor, estamos aqui enterrando mais uma mãe". Essa frase foi-nos dita durante o funeral da mãe de um homem morto por policiais militares em condições brutais, em uma incursão a uma favela do Rio, por outra "mãe de vítima", muito ativa no movimento. A figura antropomorfizada do Estado, que come e bebe enquanto permanece sentado, sem nada fazer para impedir a morte de "mais uma mãe", põe em destaque os vários planos de antagonismo entre essas unidades construídas de modo relacional e contrastivo: a fruição dos prazeres de um em choque 
com a dor de outras; a inércia de estar sentado (e omisso, portanto) ou de estar ativo no luto do funeral. O Estado aqui é evocado em sua plena dimensão de ideia, como proposto por Abrams (2006), ou seja, como entidade que tem concretude não apenas em suas formas institucionais, em sua dimensão de administração e governamentalidade, mas como entidade simbólica que atravessa e ordena o cotidiano das pessoas: aquele que faz; que deve fazer; que pode realizar ou escolher não realizar. ${ }^{13}$

Chama atenção de forma pungente que essa ideia-ente "o Estado" é, antes de qualquer coisa, masculina, do mesmo modo que do outro lado estão figuras eminentemente femininas: mães enterradas, mães que enterram. Conforme indicam, de modos distintos, Das (2008) e Brown (2006), a própria representação contemporânea (ou mito político) do Estado é constituída por e constituinte de relações de gênero. Se, como quer Das (id.), o mito teológico e político do contrato social é sempre também um contrato sexual, com implicações distintas em relação à gerência $e$ à produção da violência no âmbito doméstico e no privado, podemos pensar que estamos diante de jogos de poder entrecruzados. As "mães" tornadas protagonistas políticas, capazes de englobar simbolicamente todos os outros ativistas do mesmo movimento, sejam familiares ou não de vítimas, homens ou mulheres, falam, assim, de uma insurgência política definida em estreitas conexões com as construções - sempre em processo - de gênero. Ao falarem em nome de uma ordem doméstica que foi desfeita brutalmente pelo assassinato dos filhos, elas (e eles, no caso de demais familiares) trazem o feminino não em seus corpos

\footnotetext{
${ }^{13}$ Embora não estejamos, nos limites deste artigo, discutindo conceitualmente o que seja Estado, procuramos considerá-lo como administração, ao levar em conta sua dimensão rotineira e institucional, do modo como indicado por Souza Lima (2002) a partir de Weber (1983), mas também como processo de estatização, ou seja, como ação sempre incompleta que se exerce sobre territórios e populações ao longo do tempo, inspirando-nos nas formulações de Elias (1990) e de Tilly (1984).
} 
individuais, mas como marca de significação das relações que se romperam, bem como da violência ilegítima que as destruiu. Levam, assim, a "casa" para a cena de protesto, através do que seria o seu "centro exemplar" simbólico: a própria maternidade. ${ }^{14}$ Não à toa, mesmo em situações em que outros familiares são os membros mais ativos na militância, como irmãos ou tias, há uma expressão obrigatória dessa relação primordial, como se esses falassem por um mandato simbólico: lutam em nome da mãe que, por algum motivo, não pode estar presente.

Esse luto continuado, que tem sua memorablia mais aparente em fotos, roupas e panfletos, mas também em falas que recontam o tempo como algo que ficou "parado", da vida que ficou "acabada" ou dos corpos que ficaram doentes, produz-se ainda como uma forma de insurgência em relação àquilo que seria o outro extremo desse jogo de gênero entre os pólos morais do doméstico e do público: a legitimidade da guerra. Como lembra Butler (2004), o luto não é algo franqueado a todos e, em diversas situações, prantear os mortos publicamente significa desafiar limites políticos relevantes. Retomando o argumento de Das sobre o mito do contrato social, a contrapartida da autoridade simbólica masculina sobre o doméstico estaria justamente na obrigação, tão cara aos Estados Nacionais e a seus diagramas de distribuição da violência legítima (Das e Poole, 2004), de morrer na guerra contra os inimigos estrangeiros.

Ao levar sua destruição doméstica para as arenas públicas, as mães e familiares enfrentam essa outra verdade crucial da política e do gênero, por contestarem a justiça da guerra que colocaria seus filhos e parentes no lugar do inimigo a ser morto $e$

\footnotetext{
${ }^{14}$ A maternidade comparece aqui como uma espécie de equivalente doméstico ao que seria o "centro exemplar" do Estado, algo só possível de ser plenamente vivido no plano da representação teatralizada, como sugere a formulação de Geertz (1991) sobre o Negara. A díade mãe-filho oblitera, assim, as outras conexões familiares e não familiares presentes, de modo análogo ao que o "centro exemplar" do Estado encenado faz com as "periferias imperfeitas", que seriam suas ações cotidianas e materiais.
} 
combatido. Como discutiremos na próxima parte do artigo, não é sem motivo que o trabalho argumentativo feito nos variados locais de protesto, mas também ao longo de todo o embate judicial para condenar policiais, baseia-se na importância de provar que os mortos eram "honestos" e não "bandidos" ou "traficantes". Ou seja, para inseri-los primordialmente no mesmo lugar de direito daqueles que devem ser protegidos - e não aniquilados - pelo Estado, aqui corporificado nos policiais. Seu desafio é tecido, desse modo, necessariamente valendo-se de uma perspectiva simbólica marcada pelo gênero, através de linguagens morais $e$ emotivas que performam a falência desse masculino que ataca ao invés de proteger e que traz a guerra para a "casa".

Construir a ilegitimidade das ações policiais implica, assim, qualificar seus lugares enquanto mulheres que se insurgem contra o que lhes é muito superior em todos os planos, alardeando $e$ invertendo a direção de múltiplas desigualdades. "É essa filha da puta negra, pobre, moradora da comunidade (...) que vai botar vocês na cadeia", gritou Celeste em frente à instituição onde seu filho foi morto. $\mathrm{O}$ xingamento, que teria sido murmurado pouco antes por policiais que guardavam a entrada do prédio-prisão durante o protesto, tornava-se, naquela cena pública, combustível de identificação e denúncia. Assumindo em voz alta o designativo carregado dos mais contundentes signos de dominação, assentados nas hierarquias morais de gênero $e$ sexualidade $e$ agregando-lhe outras marcas notáveis de subordinação social, como a cor e a condição social e de moradia, Celeste devolvia o ataque que lhe havia sido feito. O desafio exacerbava seu destemor ao teatralizar tudo o que a colocava em posição de vulnerabilidade e inferioridade, produzindo uma espécie de catarse cênica dos jogos extremos de assimetria social que a constituem como sujeito socialmente posicionado.

Ao dizer onde mora, porém, ela não só colocava em cena seu destemor pessoal, mas explicitava outro ponto nevrálgico de todo o embate com a "guerra injusta" que teria vitimado seu filho e os das outras mães: a inseparabilidade entre as condições 
desiguais que atravessam os corpos e os territórios. Ao denunciar que os jovens mortos assim o foram por serem pobres, moradores de periferias ou favelas e negros em sua imensa maioria, e que por isso ficaram expostos não apenas aos riscos concretos que acabaram matando-os, mas também ao desinteresse em apurar as condições de sua morte, as mães e demais integrantes da Rede falam de processos cruéis de produção de corpos e vidas dispensáveis.

O enquadramento burocrático da maior parte dessas mortes como "auto de resistência" - figura classificatória que os relega à morte em massa e pré-justificada da guerra ${ }^{15}$ - precisa, dessa forma, ser combatido tanto em relação à singularidade dos corpos em si, trabalho que é feito construindo biografias afetivas e morais para eles, quanto aos próprios territórios. Se a individualização dos mortos procura de certo modo marcar que, independente de estarem em um território de "margem"16, recoberto de suspeitas a priori, eles não se enquadram nessas imagens dominantes e não poderiam ser atingidos pelas mesmas práticas de combate que vitimaria os "outros" ("traficantes" e "bandidos"), a requalificação dos próprios territórios precisa ser feita para que a ação em si de

${ }^{15}$ Segundo Cano (1997), "auto de resistência" é a "nomenclatura oficial que a polícia usa para definir as mortes e os ferimentos ocorridos em confronto, decorrentes da resistência à autoridade policial". Inicialmente regulamentado pela Ordem de Serviço "N", n 803, de 2 de outubro de 1969, da Superintendência da Polícia Judiciária do antigo estado da Guanabara, o "auto de resistência" foi registrado pela primeira vez no dia 14 de novembro do mesmo ano, após uma ação policial realizada por integrantes do Grupo Especial de Combate à Delinquência em Geral - grupo que também havia sido formado em 1969 e ficou conhecido como "Grupo dos Onze Homens de Ouro" (Verani, 1996).

${ }^{16}$ Recorremos aqui à formulação de "margens do estado" no sentido proposto por Das e Poole (2004:8-10): 1) periferias habitadas por pessoas tidas como insuficientemente socializadas de acordo com as leis e a ordem vigentes; 2) lugares onde os direitos podem ser violados através de dinâmicas distintas de interação das pessoas com documentos, práticas e palavras do Estado; e 3) um espaço localizado entre corpos, leis e disciplina. 
combate seja denunciada como vil e injusta. "Entram atirando", "fazem cavalo de tróia"17, "não querem saber se tem criança na rua" e outras expressões como essas procuram mostrar que a ação em si da polícia é que seria poluente do território, por torná-lo peculiarmente violento e perigoso, a partir do desprezo pela vida comum de todos que o habitariam. Mostrar, assim, não apenas que as vítimas atingidas não deveriam tê-lo sido - por serem "trabalhadores", "estudantes" ou simplesmente crianças - mas que o modo de fazer essa guerra é perverso e injustificado tornamse as duas faces da mesma moeda, pautando as atuações políticas dos familiares.

Como procuramos indicar antes, essas atuações se desenvolvem em vários espaços e ao longo de temporalidades distintas, indo da morte em si ao momento em que é tomada a decisão de denunciar a ilegitimidade dessa morte, passando ao empenho na construção em si do "caso" como processo judicial que poderia levar à condenação dos responsáveis. Nenhum desses momentos, porém, parece mais carregado de expectativas $e$ ritualidade do que o julgamento em si de acusados por uma dessas mortes. Chegar a esse momento é visto como uma vitória parcial em si mesma, considerando as dificuldades a serem enfrentadas para desmentir e contrapor a documentação que inicia burocraticamente o registro da morte como "auto de resistência". Além disso, considerando os anos que se passam ao longo de todas as etapas policiais e judiciais, o julgamento marca também a força pessoal tecida no tempo, no trabalho de manter acesa a indignação e, ao mesmo tempo, de gerir a vida ordinária, cuidando de si e dos demais, com resiliência.

É também nos julgamentos que se espetacularizam de modo mais evidente as linhas políticas e morais que subjazem a essas

\footnotetext{
${ }^{17}$ A expressão "cavalo de tróia" é utilizada no campo da segurança pública e dos Direitos Humanos para se referir à estratégia utilizada por alguns policiais de escolherem uma casa na favela onde pretendem realizar algum tipo de operação para ficarem "escondidos" durante o tempo que acharem necessário para surpreenderem os traficantes em momento oportuno.
} 
mortes, uma vez que argumentos em torno da sua legitimidade ou ilegitimidade são explicitados pelas partes profissionais envolvidas. Por esses motivos, escolhemos trazer alguns recortes a partir do acompanhamento de um julgamento recente. A ideia aqui não é oferecer uma descrição pormenorizada de fases, personagens e performances presentes na situação, mas procurar iluminar como se sustentam e se alteram certos elementos, como a relevância do lugar simbólico da maternidade e, em especial, as conexões entre dor pessoal, dor moral e dor política que se produzem nessas condições dramáticas.

\section{3. "mãe de traficante não fica lutando por justiça"}

Fórum do Rio de Janeiro, segunda-feira à tarde. Verão de novembro do lado de fora. Lá dentro, o julgamento de um policial militar. Acusação: homicídio qualificado. Tratava-se do julgamento de um dos cinco policiais denunciados pelo Ministério Público por participarem de uma incursão da polícia militar em uma favela carioca que resultou na morte de quatro moradores há quase dez anos. O julgamento havia sido adiado meses antes $e$ agora se realizava em momento especialmente tenso na cidade. Um dos principais conjuntos de favelas do Rio, conhecido como Complexo do Alemão, havia sofrido intervenção militar por tropas das Polícias Militar, Civil e Federal ${ }^{18}$, com extensa cobertura midiática e reinava na cidade certo clima triunfante $e$ de apoio às ações "contra o tráfico".

Reunimo-nos na entrada do Fórum em torno de Andreia, mãe de uma das vítimas e a única que se manteve em contato constante com a Rede e com o Núcleo de Direitos Humanos da

\footnotetext{
${ }^{18}$ Vale o registro do apoio das Forças Armadas em diferentes momentos dessa intervenção, com destaque especial para a disponibilização e utilização de veículos blindados da Marinha como o anfíbio "M-113" (o mesmo modelo que foi usado pelo exército americano na Guerra do Vietnã e em missões no Iraque) e de anfíbios "urutu", do Exército brasileiro (o mesmo modelo utilizado pelas "Forças de Paz" da ONU, no Haiti).
} 
Defensoria Pública, que agora atuaria como assistente de acusação. ${ }^{19}$ Embora houvesse outra mãe de vítima da mesma chacina ${ }^{20}$ presente, a centralidade de Andreia podia ser registrada até mesmo no modo como correntemente o julgamento era identificado, entre participantes variados desse grupo, como o "julgamento da Andreia". Como de praxe, vestimos todos e todas as camisetas com as fotos das quatro vítimas e entramos no Tribunal.

Uma vez lá, fomos nos distribuindo do seguinte modo: na primeira fila da platéia, três mulheres: as duas mães de vítimas fatais da chacina e a ex-mulher de uma dessas vítimas. As filas seguintes foram ocupadas por outros familiares de vítimas de violência policial em favelas (mães, tias e irmãos, basicamente), demais militantes da Rede e nós, pesquisadoras, somando quatorze pessoas no lado da plateia situado na frente dos jurados. ${ }^{21}$ Os familiares e amigos do réu ocuparam bancos do

\footnotetext{
${ }^{19}$ Profissionais do Núcleo de Direitos Humanos da Defensoria Pública (RJ) atuam na assistência da promotoria em processos como esse, desde 2004. Essa atuação às vezes é vista como inadequada à função de defensores públicos, porque os leva a acusar o réu ao invés de defendê-lo. A explicação dos profissionais deste Núcleo é que, enquanto defensores públicos posicionados contra violações de direitos fundamentais, é a defesa ao direito à vida o que define sua atuação como assistente de acusação.

${ }^{20}$ Optamos por reproduzir aqui o termo "chacina" usado pela militância por considerar que, sendo ele próprio resultado e efeito de posicionamentos políticos muito marcados, não haveria como definir para nós mesmas um lugar "outro" em termos das palavras. Todo o julgamento, aliás, é cortado pela oposição entre a "chacina" e a "morte em confronto", como se verá. Deixar de subscrever uma das posições é, nesse caso, correr o risco de ver-se colocado em aliança, mesmo que sutil, com o trabalho político e simbólico de naturalizar as mortes em grupo ocorridas nessas incursões policiais nas favelas.

${ }^{21}$ O Tribunal do Júri é composto por um juiz de direito, que é o seu presidente, e de vinte e um jurados que são sorteados dentre os alistados, sete dos quais constituirão o conselho de sentença em cada sessão de julgamento. O serviço do júri será obrigatório, devendo os jurados, escolhidos dentre cidadãos de notória idoneidade, serem cidadãos maiores de vinte e um anos. Constitucionalmente são assegurados para as atividades do Tribunal do Júri a plenitude de defesa; o sigilo das votações; a soberania dos veredictos; a competência para o julgamento
} 
outro lado da plateia. O réu entrou no tribunal fardado, vestindo por cima da farda o colete à prova de balas, e trazendo no braço direito (que fica virado para a plateia) a bandeira do estado do Rio de Janeiro.

Acusação e defesa deram início à montagem do júri, selecionando cinco mulheres e dois homens. ${ }^{22} \mathrm{O}$ juiz fez a leitura da denúncia e deu início ao interrogatório das testemunhas, que naquele dia foram somente duas de acusação, pois todas as outras foram dispensadas. A defesa conduziu as primeiras perguntas à testemunha, tentando reconstruir a cena do crime como se tivesse havido troca de tiros entre policiais e traficantes. A partir de então, foi iniciado um trabalho tanto do promotor quanto do próprio juiz para esclarecer o que o depoente realmente havia dito sobre o local dos fatos e a forma como o defensor público havia interpretado.

Como a versão que trabalha com a hipótese da troca de tiros transforma as vítimas da chacina em potenciais criminosos, é desenhada nesse momento a inversão que caracteriza todas as audiências de instrução e julgamento de policiais acusados de matarem moradores de favelas que observamos até essa etapa da pesquisa: o réu deixa de ser o alvo das acusações daquele julgamento, pois estas são direcionadas pela defesa para as vítimas da chacina (na situação relatada, em especial para o filho de uma das mães que estava sentada na primeira fila da plateia), fazendo com que o promotor e o assistente de acusação tivessem que se esforçar para defender as próprias vítimas. Nesse sentido, a equipe responsável pela acusação dos policiais é obrigada a usar a maior parte do tempo das audiências de instrução e julgamento

dos crimes dolosos contra a vida. (Artigo $5^{\circ}, \mathrm{XXXVIII,} \mathrm{da} \mathrm{Constituição} \mathrm{Federal} \mathrm{e,}$ Artigos 433 a 438 do Código de Processo Penal).

22 Uma das mães de vítimas sentada ao nosso lado comenta: "Não gosto muito de mulher no júri não." Perguntamos "Por quê?" e a resposta foi: "tem umas ali que não sabem nem fritar um ovo". 
"limpando moralmente"23 as vítimas e, por extensão, seus familiares. A inversão completa do quadro, portanto, faz com que durante o julgamento de um processo desse tipo, a defesa acuse $e$ a acusação defenda.

Os documentos revisitados nessa etapa do julgamento, apesar de originalmente pertencerem a arquivos distintos, passam a ser apresentados aos jurados como um mosaico de provas que garantam a coerência da argumentação da defesa (da própria vítima): carteiras de trabalho, boletins escolares, fotografias das vítimas uniformizadas e cartas de empregadores assegurando a idoneidade das vítimas são retiradas das pastas dos processos de modo análogo ao acionamento de laudos técnicos (como os laudos cadavéricos do IML) que comprovam, por exemplo, que vítimas foram atingidas com tiros de fuzil na nuca - o que tecnicamente caracteriza execução sumária. ${ }^{24}$

Após o interrogatório das testemunhas de acusação, o promotor se dirige aos jurados: "eu tô defendendo aqui o direito à vida [...] nós temos que ver o outro lado, o lado das famílias". Dedica um tempo parado em pé, de frente para o júri, descrevendo como é forjado o "kit bandido"25 para validar o

\footnotetext{
${ }^{23}$ Acionamos aqui a ideia de "limpeza moral" elaborada por Machado da Silva e Leite (2008) para analisar estratégias de enfrentamento de estigmas e de distanciamento moral dos moradores de favelas em relação aos traficantes que atuam nessas localidades.

${ }^{24}$ Os laudos cadavéricos do IML são utilizados com frequência por especialistas para descrever e comprovar diferentes "casos emblemáticos de execução sumária". Para uma análise competente sobre o IML-RJ e seu enredamento na esteira das técnicas de governo ajustadas a populações consideradas descartáveis, ver Ferreira (2009). Para descrições técnicas detalhadas de diferentes "casos emblemáticos de execução sumária", ver especialmente os relatórios do Centro de Justiça Global (2003; 2004a; 2004b) da Anistia Internacional (2003) e da ONU (Alston, 2008).

${ }^{25}$ Este "kit" é composto geralmente por uma arma de fogo (revólver ou pistola), algumas trouxinhas de maconha e/ou alguns papelotes de cocaína. É chamado de "kit bandido" por ser "plantado" por policiais junto aos corpos das vítimas (ou incluído como material apreendido na operação), para reforçar a versão de que a vítima era traficante e, portanto, aquela morte aconteceu durante um confronto
} 
posterior registro do "auto de resistência" na delegacia. Depois, explica o resultado do exame de confronto balístico ${ }^{26}$, que revelava que três vítimas da chacina haviam sido atingidas por projéteis que saíram da arma do policial a ser julgado naquele dia e diz claramente para os jurados: "se os senhores acham que extermínio é legítimo, absolvam".

Em contrapartida, o defensor do réu se dirige diretamente a uma das mães de vítima da chacina em questão e diz que respeita e que entende "a dor que todo o grupo sente", mas se volta rapidamente para a esposa do policial acusado que estava sentada no outro lado da plateia, chamando-a pelo nome e fala do filho deles, também mencionando o nome da criança. Tal defensor ainda ironiza os documentos apresentados pelo assistente de acusação anteriormente, bem como a própria atuação do Ministério Público durante o julgamento, e constrói uma versão da trajetória de uma das vítimas envolvendo antecedentes criminais. Explica para os jurados que os outros policiais que participaram dessa mesma chacina e foram julgados tinham sido absolvidos. Solicita que sua assistente leia a lista do material que foi apreendido junto aos corpos das vítimas (o "kit bandido" mencionado anteriormente) e pergunta alto: "De onde surgiu isso tudo?". Continua sua explanação seguindo a linha da criminalização das próprias vítimas e a exaltação do policial: "Se eles eram traficantes, mereceram. (...) se esses rapazes eram inocentes, o que aconteceu foi uma fatalidade. (...) $\mathrm{Ou}$ acreditamos nas forças do Estado [apontando para o réu] ou acreditamos em versões desencontradas".

Não por acaso descrevemos aqui a cena do julgamento de um dos diversos casos de violência policial em favelas qualificados

armado. A utilização do termo "vela" também é muito comum, quando ao invés do "kit bandido" é colocada somente uma arma de fogo junto aos corpos.

${ }^{26}$ No Rio de Janeiro, geralmente tal exame é realizado a partir do envio das armas utilizadas pelos policiais que participaram da incursão em questão ao Instituto de Criminalística Carlos Éboli (ICCE), no intuito de descobrir se os tiros que atingiram as vítimas partiram destas mesmas armas. 
por especialistas como "caso emblemático de execução sumária". A insistência da equipe de defesa do policial na interpretação pela via do confronto apoiava-se em documentação bastante diferente daquela acionada pela acusação, especialmente por se tratar de um processo que, em sua condição anterior de inquérito policial, foi iniciado a partir do registro de um "auto de resistência".

Lidamos aqui, portanto, com uma de muitas situações nas quais a (i)legibilidade da documentação do Estado e das ações de seus agentes interfere diretamente no processo de consolidação do controle estatal sobre populações, territórios e vidas, como ressaltam Das e Poole (2004). Seguindo essa forma de compreensão para pensar a relação Estado/margens, levamos em conta o fato de que a questão da origem da lei emerge não como o mito do Estado, mas na forma de homens cujas habilidades para representar o Estado ou para aplicar suas leis estão localizadas em uma disposição para se mover impunemente entre o que aparece na forma da lei e práticas extrajudiciais. Nesse julgamento, então, a atuação do defensor público que dedica a maior parte do tempo a acusar as vítimas da chacina se alinha à atuação dos policiais que ao retornarem da referida incursão, lavraram o registro do auto de resistência na delegacia correspondente ao seu batalhão múltiplas escalas, esferas e agências de estado aqui se intercalam, portanto, a partir, através ou em consequência ao disparo da arma do réu desse julgamento.

Esse processo não se desvincula, porém, no caso do julgamento, do uso de outra expertise cara a profissionais que atuam em tribunais de júri: a de mexer com temores $e$ valores morais mais difusos, capazes de dar sentido à competição pela veracidade possível das "provas materiais", todas postas em dúvida por cada uma das partes. É significativo notar, assim, que a defensoria não optou por (ou não julgou necessário) afirmar peremptoriamente que os mortos fariam parte do "tráfico" ou em provar sua participação em confronto armado. Ao invés disso, atuou mobilizando uma zona de sombra e dúvida, insinuando que não havia como ter certeza de sua condição de "trabalhadores". 
Um dos pontos altos dessa estratégia foi guardado, como era de se esperar, para as alegações finais. Pondo em movimento uma marcação teatral precisa, o defensor virou-se primeiro para a parte da audiência onde nos encontrávamos e, dirigindo-se a Andreia, disse que não estava afirmando que Miguel, seu filho, fosse traficante. Em seguida, virando-se para o júri, continuou:

mas os senhores viram o que uma das testemunhas falou. $\mathrm{O}$ que ele levava nas costas? Uma mochila! E todos vimos agora na televisão os traficantes fugindo da Vila Cruzeiro. E o que eles levavam nas costas? Mochilas!

Essa fala, que poderia soar cômica não fosse o que estava em jogo ali, assentava-se em lacunas estratégicas produzidas ao longo do confronto de versões sobre as mortes e sobre os mortos, preenchendo-as com o temor difuso frente a esse "outro" encarnado no "tráfico". Para enfrentá-lo, em contrapartida, estava a figura emblemática do "soldado", do guerreiro hipermasculinizado que era indicado, uma vez mais de modo bastante teatral, pelo defensor. "Esse homem, senhoras e senhores, é um ponteiro, o primeiro a entrar no morro, que vai de peito aberto, recebendo bala. Esse é um homem!".

$\mathrm{O}$ assistente de acusação, por sua vez, para contestar a suposição que havia sido levantada em relação a Miguel, postouse, durante suas alegações finais, de frente para os membros do júri, mas próximo à parte onde estavam os familiares e militantes. Indagou, então, "Como eu sei que Miguel não era traficante? Porque D. Andreia está aqui. E mãe de traficante nenhuma fica anos lutando por justiça". O embate havia migrado, portanto, da trajetória moral das vítimas para a trajetória moral e política das mães, centrando-se, não à toa, em Andreia, a única que havia permanecido durante anos em contato com as instâncias de Estado e com a militância. Era sua tenacidade que comprovava a impossibilidade de Miguel ser traficante, porque "mãe de traficante" não faria o mesmo. É produzida uma espécie de 
inseparabilidade entre ambos, que torna ainda mais pungente a expressão corrente de que aquele era o "julgamento da Andreia".

A zona de confusão mobilizada durante o julgamento entre acusação e defesa, entre "traficantes" e "trabalhadores" encontrava nos corpos morais das mães um ponto de ordenação, uma linha divisória que parecia oferecer a clareza que os significados sociais atribuídos ao território "misturado" $e$ potencialmente inimigo das favelas não permitia. A contrapartida do filho criado para ser "trabalhador" era dada ali pela figura da mãe que não admitia viver privadamente sua dor $e$ que se empenhava em conseguir esse bem supremo de redenção $e$ reconhecimento dado pela condenação dos policiais que $\mathrm{o}$ mataram. Seu oposto simbólico, a "mãe de traficante" aparecia na fala como sua imagem às avessas, dizendo-nos da aquiescência em relação à ilegitimidade e à impossibilidade de exigir justiça, de prantear publicamente sua dor, tornando-se tão anônimas quanto os corpos dos filhos mortos "em confronto".

Menos que na espetacularidade da raiva, porém, era na força moral da resiliência e, portanto, na gerência do tempo, que se assentava esse mérito materno posto em destaque pelas falas dos profissionais. Como chamou atenção, em outra passagem do julgamento, o promotor principal: "Eu tenho quase sessenta anos e não vou compactuar com covardia [...] desde 2003 essas mães estão aqui pedindo justiça". Marcando o tempo também em sua própria trajetória, com a idade funcionando como uma espécie de fiança moral, o promotor evocava o valor da espera, da não desistência, da difícil continuidade exigida nesse trabalho de "pedir justiça". Ao fazê-lo, cabe notar ainda que ele apontou para o lado da platéia onde estávamos, englobando todos e todas ali situadas, com nossas camisetas, sob o designativo "essas mães". Nesse momento, mais que em qualquer outro, foi possível perceber que tal maternidade era um designativo produzido em efeito, e não apenas uma condição social específica. Podíamos ser tornados "essas mães" porque ali compartilhávamos e performávamos um modo específico de habitar o espaço público e 
de "pedir justiça", ancorado na força do laço representado como o mais vital $e$ inquestionável culturalmente e em uma estética específica do sofrimento. $\mathrm{O}$ apagamento de todas as outras possíveis inserções, sejam elas do ponto de vista do parentesco com as vítimas, sejam do ponto de vista da participação nesse coletivo, não se fazia naquela situação, como em inúmeras outras, por descuido ou imprecisão, portanto. A luta "das mães" nos fala de tentativas de inscrever como importantes no espaço público certas mortes tomadas a priori como desimportantes, como "baixas" de guerra, mobilizando para tanto o que seria o signo máximo da localização social dos corpos como pessoas, sua condição moral e afetiva como filhos de uma mulher. "Confie nos jurados, D. Andreia", foi a frase que encerrou as alegações da promotoria.

O policial foi absolvido.

\section{Algumas considerações finais}

Terminado o julgamento, já perto de uma da manhã, saímos do Fórum em pequenos grupos, ponderando o peso que aquele momento específico vivido no Rio de Janeiro poderia ter desempenhado no resultado final, mas lembrando também que as absolvições são o desfecho mais comum nesses casos. Conversando com Andreia, do lado de fora, do prédio expressamos admiração pela calma impressionante que ela manifestava depois de tudo o que fora visto e ouvido ali. Ela então nos contou que Miguel tinha avisado-a, através de um sonho, que a justiça viria, mas que ainda não seria daquela vez. Com isso, sentia-se preparada para o que tinha acontecido.

Os sonhos, bem como as premonições relacionadas posteriormente ao dia da morte, parecem desempenhar papel ativo na gestão do luto e no reordenamento da vida cotidiana. ${ }^{27}$

${ }^{27}$ Lucila, cujo filho foi morto na Polinter, contou-nos que estava em casa, passando roupa e se preparando para visitá-lo quando ouviu claramente Padre Marcelo, a quem estava acompanhando no rádio, dizer-lhe "seu filho já não está 
Através deles, elas não apenas conectam-se aos filhos e irmãos mortos, mas reorganizam suas possibilidades de ação, fortalecem seus corpos ao receberem avisos sobre a necessidade de se cuidarem mais ou ao simplesmente aplacarem parte do sofrimento que, segundo suas falas, está na base das doenças constantes que lhes atingem. O filho, que aparece em sonho para aquietar a mãe dizendo que está bem ou para preveni-la em relação ao que vai acontecer, não é uma imagem vaga, mas um ator ativo nesse processo, que continua a agir no tempo, permitindo-lhe um presente menos pesado e oneroso.

Por outro lado, as premonições que são revistas continuamente falam de outra relação entre o tempo e a ação social. $\mathrm{O}$ aperto no peito, o sentimento de que algo ruim iria acontecer, a mensagem vinda pelo programa de rádio ou $\mathrm{O}$ sangramento inexplicável no instante da morte dizem-nos da impotência naquele instante, da incapacidade de impedir algo que estava ocorrendo ou que iria ocorrer. Nesse sentido, falam do cuidado que não foi possível ofertar, ao contrário do cuidado que agora, às avessas e com sorte, é-lhes trazido pelos mortos nos (poucos) sonhos confortadores. A conexão das redes familiares com seus mortos está atravessada o tempo todo por essas ações e repertórios de cuidados que foram cumpridos, como no caso dos filhos estudiosos e trabalhadores; que foram cassados, como nas situações dos que foram mortos enquanto estavam detidos em unidades prisionais de escopo variado; e que agora são tecidos através do esforço continuado da "luta".

A ação política de busca de justiça para esses mortos está diretamente ligada, desse modo, ao esforço em não deixar que se apaguem também essas histórias familiares, levando os vivos para o mesmo terreno de desimportância a que os mortos estariam

aqui, mãezinha", tendo certeza nesse momento que "algo de muito ruim tinha acontecido". Silvana teve um sangramento inexplicável no momento em que seu irmão foi morto por policiais na mesma favela onde mora e ainda hoje tem visões dele. Além delas, outras mães e parentes - sempre mulheres - mencionam também ter sonhos constantes com os mortos. 
sendo relegados. As fotos, geralmente sorridentes, escolhidas para as faixas, banners e camisetas têm sua contrapartida nas imagens de autópsias e de corpos exumados que, às vezes, são carregadas em pequenos álbuns nas bolsas ou em relatórios de perícia encadernados que são seletivamente abertos. ${ }^{28} \mathrm{Em}$ cada grupo de imagens, a exibição da vida e o congelamento brutal da morte revelam mais que corpos individualizados. Ali estão presentes, em negativo, as relações que possibilitaram ou causaram a forma que esses corpos assumiram em cada momento, simbolizadas nas falas através dos epítetos antagônicos das "mães" que deram a vida e do "Estado" que a tirou, como discutido antes. Os corpos feitos e desfeitos nesse processo são matéria de gestão e produção afetiva, administrativa e política, surgindo e ressurgindo como efeito dos modos pelos quais são enunciados a cada momento. Ora são corpos marginais e bandidos, que "mereceram a morte que tiveram", ora são corpos amados e bem criados, com sorrisos abertos nas fotos selecionadas ${ }^{29}$, ora são corpos incorpóreos, que vêm em sonhos para perpetuar a relação que foi interrompida e o futuro que foi roubado.

Esse confronto simbólico não pode ser entendido, a nosso ver, senão como localizado no cerne das tramas e fazeres da

\footnotetext{
28 Situação semelhante foi observada por Paula Lacerda durante seu trabalho de campo em Altamira/PA. Uma das mães lhe relatou que por muito tempo ela levava em sua bolsa um álbum de fotografia dos corpos das vítimas, tal como foram encontrados em meio à mata. Com isso, ela pretendia sensibilizar os políticos, gestores ou demais sujeitos com quem precisasse falar (Lacerda, 2011b).

${ }^{29}$ A apresentação da imagem do filho, o cuidado na seleção das fotografias que serão estampadas nas camisetas, coladas ou impressas em cartazes, constitui o que Leite (2004:170) designou como "foto-símbolo" - "a foto originalmente cedida à mídia para identificar a vítima (...) é a que permite uma identificação mais imediata do 'caso' por ongs, jornalistas e pelo público em geral (...) a fotografia escolhida deve realçar os atributos que se quer destacar ou a que se quer aludir (a pouca idade, as qualidades morais, a condição de estudante, a alegria/vitalidade etc.) e, neste sentido, integra a narrativa das mães sobre a impropriedade e o absurdo daquela morte."
} 
biopolítica (Foucault, 2000). O privilégio público dado ao vínculo materno sublinha a centralidade da reprodução material e moral de pessoas como parte do governo de populações tomadas como potencialmente perigosas. Como explicitou, sem qualquer sutileza, um governador de Estado, a ênfase nas ações de segurança pública nas favelas se faria necessária por estarmos diante de "verdadeiras fábricas de marginais" ${ }^{30}$ Lidos do ponto de vista de sua fabricação física e moral, por sua vez, esses mesmos corpos que povoariam os territórios perigosos na condição de marginais, seriam fruto não do espaço, mas do sangue, do útero e do trabalho moral de suas mães. A preocupação em mostrar que "criou direito", que o filho "estava estudando" ou que cometeu um erro, mas que poderia se regenerar "já que na família não havia bandido", refaz o percurso da reprodução, tornando-as a miragem espelhada daqueles que teriam nascido de seus próprios corpos.

O trânsito entre a linguagem das ações morais que as fizeram boas mães $e$ a linguagem da natureza inexprimível do sangue e do corpo permite $e^{31}$, por sua vez, que se abram certas possibilidades estéticas estratégicas para enunciação do sofrimento $e$ da indignação que as conectam à luta coletiva, mas nunca as reduzem a ela. Há sempre um resíduo que é anunciado, paradoxalmente, na afirmação da impossibilidade de comunicar plenamente o sofrimento. Frases como "eu não sei como estou aqui", "só quem é mãe sabe", mas também gestos, suspiros, um balançar da cabeça em negativa no meio de uma frase

\footnotetext{
${ }^{30} \mathrm{~A}$ relação Estado/margens que desenha esse enquadramento corpos-fábricas pode ser compreendida como base para uma "proposta de tratamento epidemiológico da população favelada", conforme sugere a análise de Birman (2008).

${ }^{31}$ A coexistência e a competição estratégica entre os argumentos do "sangue" e do valor de "criar" são discutidas por Fonseca (2004) e por Vianna (2005) em diferentes situações de disputa moral.
} 
interrompida vão preenchendo as falas com marcas desse indizível da dor. ${ }^{32}$

Em outras situações, porém, pode ser exatamente o acionamento de um substrato comum que as ligaria a outras mães o que lhes oferece a licença para não falar tudo ou para colocar outros significados e valores no que foi dito. Lucila, mãe de um rapaz morto enquanto estava detido na Polinter, saiu de um encontro com a Chefe da Polícia Civil do Rio de Janeiro convencida de que o inquérito relativo à morte do filho agora finalmente teria prosseguimento. Após uma manifestação em frente à Sede da Polícia Civil, no centro do Rio, Lucila conseguiu ser atendida, com mais dois militantes da Rede, pela Chefe. Ao descer, contou a nós e aos demais manifestantes que dessa vez estava confiante de que progressos seriam feitos, porque a policial havia ficado comovida com o caso que ela lhe expusera e se comprometido a olhar pessoalmente por ele, promessa reforçada pelo vínculo familiar e afetivo estreito que manteria com um rapaz que teria o mesmo nome do filho de Lucila. A confiabilidade que o cargo não havia sido suficiente para garantir parecia ali ser conseguida através do compartilhamento mais profundo dado pelo afeto e pela coincidência dos nomes escolhidos.

Há ainda uma profunda associação entre esse indizível da dor materna - que oblitera, como já dissemos em várias passagens, todas as outras relações - e o modo como, em certos momentos, o sofrimento pode ser performado em estreita ligação com a insanidade ou a "loucura". Desafiar os limites do perigo dizendo em público seu endereço e afirmando-se como a "filha da puta negra e pobre" que provoca os policiais a "baterem na sua porta", como o fez Celeste; subir ao local onde o filho foi executado e ali fotografar, sozinha, as provas que restavam para que essas fossem, um dia, consideradas no inquérito, como fez Claudia, mãe de um rapaz morto em uma favela da zona norte; ou simplesmente ameaçar "fazer a louca", como expressou uma

${ }^{32}$ Usamos a noção de "indizível" no sentido proposto por Pollak, 1982. 
das militantes mais antigas da Rede frente a uma situação que lhe causava indignação, ao mesmo tempo em que nos confidenciava, preocupada, que "dá uma loucura às vezes nas mães", são formas de constituir esse bordado sinuoso entre a sanidade e a insanidade que aparece em falas e atos. Se a loucura como acusação pode ser positivada em alguns casos, sendo o das "locas de la Plaza de Mayo" talvez um dos mais célebres ${ }^{33}$, cremos que isso se deve também à força de certas propriedades simbólicas estreitamente ligadas ao feminino e, mais especificamente, à maternidade. Aparecendo nas cenas públicas não como sujeitos individualizados, mas como sujeitos da díade mãe-filho, elas se apresentariam, nesses limites estéticos da "loucura" anunciada por elas mesmas ou atribuída por outros, como corpos sempre incompletos e abertos por causa da perda.

"Os netos que não conhecemos: presente!". Com essa saudação, feita por mães e familiares de diferentes movimentos do Rio de Janeiro e de São Paulo durante uma das vigílias que marcam todo ano a data da "chacina da Candelária", foram recordados não apenas os mortos, que eram chamados por seus nomes e aos quais se seguia a expressão ritual "presente!", mas aqueles que ainda não tinham nascido e nunca nasceriam, os filhos virtuais deles, os "netos". A indignação, o vazio e o sofrimento mencionados em relação àqueles que foram assassinados ganhavam, assim, outros contornos e outro tempo. Falava-se aqui de uma perda no futuro, de um lugar que se

${ }^{33}$ Quando Jean-Pierre Bousquet, correspondente da Agência Fance Press na Argentina, em 1977, contou a uma das madres a forma como os milicos se referiam a elas, ouviu a seguinte resposta: "!Locas! Es todo lo que encuentran para contestar, son unos crápulas. Un periodista de Buenos Aires Herald ya me lo había dicho. Después de todo, tienen razón, hay que estar bien locas para desafiarlos abiertamente cuando todos tiemblan frente a ellos. Hay motivos suficientes para volverse loca, después de buscar en vano durante vários meses a un ser amado, tropezando constantemente con la indiferencia y la hostilidad del mundo que nos rodea" [...] Las locas..., las locas de Plaza de Mayo, He ahí un bonito nombre de guerra. Está adoptado. Escribirlo así y que también tus colegas lo hagan" (Gorini, 2006:89). 
extinguiu para sempre e que ficava adiante, no devir, no imaginado. O "direito de ser Mãe" com que abrimos o texto surgia renovado e perpetuado nessa nova geração que podia ser pranteada sem nunca ter nascido. O significado social maior da maternidade como produção de conexões vitais no tempo, mas também fora dele, era, desse modo, alardeado em frente à principal catedral do Rio de Janeiro.

Durante o acompanhamento desses percursos, marcados por tantos enfrentamentos, sofrimentos, recuos, posicionamentos, silêncios, discursos, passeatas, vigílias, premonições, sonhos, orações e julgamentos, talvez o que se revele como mais desafiador a ser observado seja a competência dessas mulheres $e$ homens para se moverem nesse duplo limite político da perda pessoal e da ação coletiva, dos vivos e dos mortos, da contenção e do desvario, do cotidiano e do extraordinário. Longe de esgotar as ações, estratégias e sentimentos que vêm sendo partilhados conosco nesse tempo, tentamos, com esse artigo, trazer algumas inquietações e interpretações (parciais, como sempre) do que nos tem cabido ao participar nas bordas dessa guerra.

\section{Referências bibliográficas}

ABRAMS, Philip. Notes on the difficulty of studying the state. In: SHARMA, Aradhana; GuPTA, Akhil. (eds.) The anthropology of the state: a reader. Oxford, Blackwell Publishing, 2006, pp. 112-130.

ARAUJO, Fabio A. Falta alguém na minha casa: desaparecimento, luto, maternidade e política. In: LiMA, Roberto Kant de. (org.) Antropologia e Direitos Humanos V. Brasília, Booklink, 2008, pp. 166-225.

BERMÚDEZ, Natalia. Una antropología sobre los valores morales, las clasificaciones y jerarquizaciones de muertes justas e injustas en la ciudad de Córdoba. In: CATELA DA SILVA, Ludmila. (comp.) Etnografías sobre violencias en el interior del país. Paidós, Buenos Aires. (no prelo). 
BIRMAN, Patricia. Favela é comunidade? In: MACHADO DA SILVA, L.A. (org.) Vida sob cerco: violência e rotina nas favelas do Rio de Janeiro. Rio de Janeiro, FAPERJ/Nova Fronteira, 2008, pp. 99-114.

e LEITE, Márcia Pereira. (orgs.) Um mural para a dor: movimentos cívico religiosos por justiça e paz. Brasília, Pronex/CNPq, Porto Alegre, Ed. UFRGS, 2004.

BOSTANSKI, Luc. El Amor y la Justicia como competencias: tres ensayos de sociología de la acción. Buenos Aires, Amorrortu Editores, 2000 [1990].

BOURDIEU, Pierre. La délégation et lê fetichisme politique. Actes de la Recherche en Sciences Sociales, n 52-53, 1984, pp.49-55.

BROWN, Wendy. Finding the man in the State. In: SHARMA, Aradhana; GUPTA, Akhil. (ed.) The anthropology of the state: a reader. Oxford, Blackwell Publishing, 2006, pp.187-210.

BUTLER, Judith. Precarious Life: the powers of mourning and violence. London/NY, Verso, 2004.

CAno, Ignacio. Letalidade da Ação Policial no Rio de Janeiro. Rio de Janeiro, ISER, 1997.

CATEla, Ludmila. Situação-limite e memória: a reconstrução do mundo dos familiares de desaparecidos da Argentina. São Paulo, Hucitec, Anpocs, 2001.

COMERFORD, John. Fazendo a luta. Rio de Janeiro, Relume-Dumará, 1999.

DAS, Veena. Violence, Gender and Subjectivity. Annual Review of Anthropology, 37, 2008, pp.283-99.

. Life and Words: Violence and the descent into the ordinary. Berkeley, University of California Press, 2007.

e POOLE, Deborah. State and its Margins: Comparative ethnographies. In: DAS, V. e POOLE, D. Anthropology in the Margins of the State. New Mexico, School of American Research Press, 2004.

ELIAS, Norbert. O processo civilizacional. Investigações sociogenéticas e psicogenéticas. Lisboa, Publicações Dom Quixote, vol. 2, 1990. 
A guerra das mães

FARIAS, Juliana. Quando a exceção vira regra: os favelados como população matável e sua luta por sobrevivência. Teoria \& Sociedade, 15 (2), 2008, pp.138-171.

FERREIRA, Letícia C. M. O desaparecimento de pessoas no Brasil contemporâneo: a ausência de pessoas como matéria-prima de um problema social. In: VIANNA, Adriana. (org.) Direitos Diferenciados $e$ Experiências de Desigualdade. Rio de Janeiro, E-Papers/Laced, 2011 (no prelo)

- Dos autos da cova rasa: a identificação de corpos nãoidentificados no Instituto Médico-Legal do Rio de Janeiro. Rio de Janeiro, FINEP/E-papers, 2009.

FONSECA, Cláudia. Família, Fofoca e Honra: Etnografia de relações de gênero e violência em grupos populares. Porto Alegre, Ed. UFRGS, 2004.

FouCAUlt, Michel. Em Defesa da Sociedade. São Paulo, Martins Fontes, 2000.

FREIRE, Jussara. Quando as emoções dão formas às reivindicações. In: COELHO, Maria Claudia e REZENDE, Claudia Barcellos. (orgs.) Cultura e Sentimentos - Ensaios em antropologia das emoções. Rio de Janeiro, FAPERJ, 2010, pp.168-196.

GeERTZ, Clifford. Negara. O Estado Teatro no Século XIX. Lisboa/São Paulo, Difel/Bertrand Brasil, 1999.

GOFFMAN, Erving. Frame analysis. An essay on the organization of experience. London, Harper and Row, 1974.

GoRINI, Ulises. La rebelión de las Madres. Historia de las Madres de Plaza de Mayo. Tomo I (1976-1983). Buenos Aires, Grupo Editorial Norma, 2006.

LACERDA, Paula. Polícia e Movimento Social em Altamira-Pará: o "caso dos meninos emasculados". In: VIANNA, Adriana. (org.) Direitos Diferenciados e Experiências de Desigualdade. Rio de Janeiro, EPapers/Laced, 2011 (no prelo).

Mobilização social e família no contexto da Transamazônica: articulação de familiares em torno do Comitê em 
Defesa da Vida da Criança Altamirense. Paper apresentado no Seminário Família: Aspectos Contemporâneos. Universidade Federal Rural do Rio de Janeiro (UFRRJ), mimeo 2001.

LATOUR, Bruno. Les Microbes. Guerre et Paix Suivi de Irréductions. Paris, Métailié, 1984.

LEITE, Márcia. As mães em movimento. In: BIRMAN, Patrícia; LEITE, Márcia Pereira. (orgs.) Um mural para a dor: movimentos cívicoreligiosos por justiça e paz. Porto Alegre, Editora da UFRGS, 2004, pp.141-190.

MaChado DA Silva, Luiz Antonio e LeITE, Márcia. Violência, Crime e Política: o que os favelados dizem quando falam desses temas? In: MACHADO DA SILVA, L. A. (org.) Vida sob cerco: violência e rotina nas favelas do Rio de Janeiro. Rio de Janeiro, FAPERJ/Nova Fronteira, 2008, pp.47-76.

Movimentos MÃEs DE MAIO. Mães de Maio: do luto à luta. São Paulo, Movimento Mães de Maio, 2011.

POLLAK, Michael. Des mots qui tuent. Actes de La Recherche en Sciences Sociales, 41, février 1982, pp.29-46

SOARES, Barbara Musumeci; MouRA, Tatiana; AfONSO, Carla. (orgs.) Auto de resistência: relatos de familiares de vítimas da violência armada. Rio de Janeiro, 7Letras, 2009.

SouZA LIMA, Antonio Carlos. Sobre gestar e gerir a desigualdade: pontos de investigação e diálogo. In: SoUZA LIMA, Antonio Carlos. (org.) Gestar e Gerir: Estudos para Uma Antropologia da Administração Pública no Brasil. Rio de Janeiro, Relume-Dumará, 2002, pp. 11-21

TILLY, Charles. Big structures, large processess, huge comparisons. New York, Russel Sage Foundation, 1984.

VERANI, Sérgio. Assassinatos em Nome da Lei [Uma Prática Ideológica do Direito Penal]. Rio de Janeiro, Alderbarã, 1996.

VIANNA, Adriana R. B. Direitos, Moralidades e Desigualdades: Considerações a partir de processos de guarda de crianças. Antropologia e Direitos Humanos 3. Prêmio ABA/FORD. Niterói, EdUFF, 2005, pp. 13-67 
A guerra das mães

WeBER, Max. Economía y sociedad. Mexico, Fondo de Cultura Económica, 1983.

\section{Documentos:}

Alston, Philip. Relatório do Relator Especial de execuções extrajudiciais, sumárias ou arbitrárias (Documento ONU A/HRC/11/2/Add.2). Disponível em: http://www.extrajudicialexecutions.org/. Acesso em: 10/06/2010, 2008.

ANISTIA INTERNACIONAL. Rio de Janeiro: Candelária e Vigário Geral, 10 anos depois. Londres, Amnesty International Publications, 2003.

JustiçA Global. Direitos Humanos no Brasil 2003. Relatório Anual do Centro de Justiça Global. Rio de Janeiro, Justiça Global, 2003.

JuSTiÇA GlOBAL. Execuções sumárias no Brasil - 1997/2003. Rio de Janeiro, Justiça Global/Núcleo de Estudos Negros, 2003.

JUSTIÇA GlOBAL. Relatório RIO: Violência Policial e Insegurança Pública. Rio de Janeiro, Justiça Global, 2004.

\section{Outros/documentário}

Entre muros e favelas. Direção de Susanne Dzeik, Kirsten Wagenschein e Márcio Jerônimo. Brasil-Alemanha, 2005, 60 min, cor.

Luto como mãe. Direção de Luis Carlos Nascimento. Brasil, 2009, 70 minutos, cor. 